medRxiv preprint doi: https://doi.org/10.1101/2020.03.28.20046102; this version posted March 30, 2020. The copyright holder for this preprint (which was not certified by peer review) is the author/funder, who has granted medRxiv a license to display the preprint in All rights reserved. No reuse allowed without permission.

\title{
Brief Report: Correlation cannot be used to compare sequencing panels used for the assessment of tumor mutational burden in non-small cell lung cancer.
}

\author{
Simon Heeke ${ }^{1,2,3}$, Jonathan Benzaquen ${ }^{3,4}$, Véronique Hofman ${ }^{1,2,3}$, Elodie Long-Mira ${ }^{1,2,3}$, Virginie \\ Lespinet ${ }^{1}$, Olivier Bordone ${ }^{1}$, Charles-Hugo Marquette ${ }^{3,4}$, Hervé Delingette ${ }^{5}$, Marius Ilié ${ }^{1,2,3}$, Paul \\ Hofman ${ }^{1,2,3}$
}

1) Laboratory of Clinical and Experimental Pathology, Pasteur Hospital, Université Côte d'Azur, 30 avenue de la voie romaine, 06000 Nice, France

2) Hospital-related biobank (BB-0033-00025), Pasteur Hospital, Université Côte d'Azur, 30 avenue de la voie romaine, 06000 , Nice, France

3) FHU OncoAge, Pasteur Hospital, Université Côte d’Azur, 30 avenue de la voie romaine, 06000, Nice, France

4) Pulmonary Department, Pasteur Hospital, Université Côte d'Azur, 30 avenue de la voie romaine, 06000 Nice, France

5) Epione Project-Team, Inria, Université Côte d'Azur, 2004 route des Lucioles, 06902 Sophia Antipolis, France

Corresponding author: Paul Hofman, Laboratory of Clinical and Experimental Pathology, Pasteur Hospital, Université Côte d'Azur, 30 avenue de la voie romaine, 06000 Nice, France, phone: +33-492038855, email: hofman.p@chu-nice.fr

Funding: This work has been partially funded by the Canceropôle PACA, the Ligue Départemental 06 de Lutte contre le cancer, the Conseil Départemental 06, and the French government through the LABEX SIGNALIFE program with the reference number ANR-11-LABX-0028-01 and the UCIEDI program, with the reference number ANR-15-IDEX-01, as well as by the French Association for Cancer Research (ARC) by the Canc'air Genexposomics grant. The funding organizations had no role in the design and conduct of the study.

Conflicts of Interest: Simon Heeke has received honoraria from Qiagen and Boehringer Ingelheim. Marius Ilié has received honoraria from Roche, Merck \& co, AstraZeneca, BMS and Boehringer Ingelheim. Paul Hofman has received honoraria from Roche, AstraZeneca, BMS, Novartis, Merck, MSD, Bayer, Qiagen, Thermo Fisher and Biocartis. All other authors have no conflict of interest to declare. 
medRxiv preprint doi: https://doi.org/10.1101/2020.03.28.20046102; this version posted March 30, 2020. The copyright holder for this preprint (which was not certified by peer review) is the author/funder, who has granted medRxiv a license to display the preprint in All rights reserved. No reuse allowed without permission.

\begin{abstract}
Introduction

Tumor mutational burden (TMB) has been proposed as a novel predictive biomarker for the stratification of patients undergoing immune-checkpoint inhibitor (ICI) treatment in non-small cell lung cancer (NSCLC) patients. The assessment of TMB has recently been established using large targeted sequencing panels and numerous studies are ongoing to harmonize the TMB assessment. However, usually "correlation" has been used to evaluate the association between the respective panels and we hypothesized that correlation might overestimate the comparability especially in lower TMB values, thus limiting the joint analysis of targeted sequencing panels for the assessment of TMB.
\end{abstract}

\title{
Methods
}

Thirty NSCLC samples from patients undergoing ICI treatment were consecutively sequenced using three large targeted sequencing panels: FoundationOne, Oncomine TML and QiaSeq TMB, respectively. TMB values were compared in the whole patient population and in a subset of patients where the TMB assessed by FoundationOne was between 5-25 mutations/Mb. Prediction of durable clinical benefit (DCB; $>6$ months no progression) was assessed using receiver operator characteristics and optimal cut-off values were calculated using Youden's J.

\section{Results}

Correlation between the targeted sequencing panels was strong in the whole patient population between the three panels $\left(R^{2}>0.79\right)$ but was dramatically reduced in the subset of patients with TMB 5-25 mutations/Mb. All panels were able to predict DCB in the TMB high population.

\section{Conclusions}

Assessment of TMB using the three targeted sequencing panels was possible and predictive of response to $\mathrm{ICl}$ treatment but "correlation" was an inappropriate measurement to assess the association between the respective panels.

Keywords: Tumor mutational burden, NSCLC, FoundationOne, Oncomine TML, QiaSeq 
medRxiv preprint doi: https://doi.org/10.1101/2020.03.28.20046102; this version posted March 30, 2020. The copyright holder for this preprint (which was not certified by peer review) is the author/funder, who has granted medRxiv a license to display the preprint in perpetuity.

All rights reserved. No reuse allowed without permission.

\section{Introduction}

Tumor mutational burden (TMB) has been proposed as a novel biomarker for the prediction of response to immune-checkpoint inhibitors (ICls) in non-small cell lung cancer (NSCLC) patients as well as in other cancer entities ${ }^{1,2}$. While TMB has been initially assessed using whole exome sequencing (WES), targeted sequencing panels have been designed for the precise calculation of TMB as this is a more feasible approach for routine clinical practice ${ }^{3}$. However, the assessment of TMB is not standardized across these panels, thus limiting the implementation of TMB in daily practice ${ }^{4}$. We and others have compared the TMB between two targeted sequencing panels relying mainly on "correlation" as a mathematical measurement to determine the comparability of these panels and we could demonstrate good correlation between them ${ }^{4-6}$. However, "correlation" is dominated by very high TMB values and consequently "accuracy" defined by the number of samples that are correctly determined to be TMB high has been proposed as a better measurement for the comparison of panels for TMB assessment ${ }^{7}$. It is noteworthy that this proposition has been made using in silico analysis and has not been validated on real sequencing data ${ }^{7}$. Here, we report for the first time the comparison of three different targeted sequencing panels used for the assessment of TMB in a real-life cohort of 30 NSCLC patients with a special emphasis on the precise selection of TMB-high patients.

\section{Materials \& Methods}

30 patients with advanced or metastatic lung adenocarcinoma who were treated with checkpoint inhibitors were included consecutively from routine clinical care (Supplementary Table 1). TMB was assessed using the Oncomine TML panel (OTML; Thermo Fisher Scientific, Waltham, USA) and the FoundationOne test (FO; Foundation Medicine, Cambridge, USA) as described previously ${ }^{5}$. Additionally, the QiaSeq TMB panel (Qiagen, Hilden, Germany) has been used with the same DNA as used for the Oncomine TML panel, strictly following the manufacturer's instructions and $40 \mathrm{ng}$ of DNA was used for the sequencing runs. Prior to library preparation, DNA was treated with Uracil DNA glycosylase (UDG) to reduce artefacts introduced by deamination as published previously ${ }^{5}$. Sequencing was performed on an Ion S5 sequencer (Thermo Fisher Scientific) and two samples were multiplexed per lon 540 chip. Data was analyzed using CLC Genomics Workbench 12 (Qiagen). The different sequencing panels including number of genes are further highlighted in Supplementary Table 2. The number of identical genes used across the respective panels is shown in Supplementary Figure 1. Additionally, clinical data was collected, and clinical response was assessed using RECIST v1.1 criteria. Durable clinical benefit (DCB) defined by $>6$ months with no progressive disease has been assessed to define the cut-off values for the TMB-high population using receiver operator characteristics and Youden's J. The study was performed in accordance to the guideline of the declaration of Helsinki and was approved by the local ethics committee (CHUN, IE-2017-905). All patients provided written informed consent.

\section{Results \& Discussion}

We analyzed the correlation between the two in-house tests (OTML and QiaSeq) to the outsourced FoundationOne assay (FO). As seen in Figure 1A, both in-house tests were well correlated to the FO assay with $R^{2}=0.819$ for the OTML and $R^{2}=0.785$ for the QiaSeq panel. However, we hypothesized that the correlation in the lower TMB range was much more relevant as the separation of TMB-high and TMB-low patients usually takes places at TMB values at around $10-15$ mutations/Mb ${ }^{2,4,5,8}$. We have previously established a cut-off of 15 Mutations/MB using the FO panel to determine the TMB high population ${ }^{5}$. Consequently, we have analyzed the correlation of the panels only selecting samples where the TMB as determined by FO was between 5 and 25 mutations/Mb \pm 10 
medRxiv preprint doi: https://doi.org/10.1101/2020.03.28.20046102; this version posted March 30, 2020. The copyright holder for this preprint (which was not certified by peer review) is the author/funder, who has granted medRxiv a license to display the preprint in All rights reserved. No reuse allowed without permission.

Mutations/MB away from the cut-off) (Figure 1B). Interestingly, the $R^{2}$ dropped dramatically to 0.0966 for OTML and 0.2453 for the QiaSeq panel, respectively (Figure 1B), demonstrating the very low correlation in this subset of tumors. It is noteworthy that for the in-house panels, a separate DNA extraction was used, compared to the FO panel where we had to send out tissue sections for the analysis. We tried to reduce the variation by using adjacent sections for the in-house extraction and FO but intra-tumoral heterogeneity might certainly explain some of the observed effects $5,9,10$. Additionally, while the two in-house panels only use non-synonymous mutations for the calculation of TMB, the FO assay also includes synonymous mutations ${ }^{3}$.

Consequently, we also assessed the correlation of the two in-house panels where the same DNA was used for the sequencing. However, while the two panels seemed to be strongly correlated (Figure 1C), we also saw a dramatic drop of the correlation when filtering for patients with a TMB from 5-25 mutations $/ \mathrm{Mb}$ (from $R^{2}=0.9349$ to $R^{2}=0.5823$; Figure 1D). Correlation values including the $95 \%$ confidence interval are further summarized in Supplementary Table 3. Poor agreement between pairs of panels using the Bland Altman method ${ }^{11}$ can also be observed on Supplementary Figure 2, for the whole as well as the filtered populations. Interestingly, transformation of data using z-scores has been recently proposed to increase comparability between sequencing panels in an in silico approach, however, the authors noted that very high populations (>900 patients) are needed to perform this transformation with adequate statistical power ${ }^{12}$ which was not possible in this cohort.

As correlation was clearly an inappropriate measurement to compare the different panels, we tested if TMB using the respective panels was able to predict response under ICI treatment in this series of NSCLC patients independently. All three panels predicted durable clinical benefit in this cohort with an area under the curve in ROC curves (AUROC) of FO $=0.8487$, AUROC OTML $=0.7763$ and AUROC QiaSeq $=0.6875$ (Figure 2A). As expected, the cut-offs at which the TMB-high population was classified according to the Youden's J analysis differed between the three panels with a cut-off of $\geq$ 14 mutations/Mb for $\mathrm{FO}, \geq 9.3$ mutations/Mb for OTML and $\geq 11.1$ mutations/Mb for the QiaSeq panel, respectively (Figure 2A) ${ }^{6}$. Likewise, progression-free survival (PFS) was prolonged in the TMBhigh population (Figure 2B), independent of which panel was used. This indicates that, despite the low correlation between the panels, they were equally able to predict response to treatment, thus highlighting the fact that correlation cannot be used for the comparison of large sequencing panels used for TMB assessment. Consequently, only a subset of 6 patients was equally classified to be TMBhigh across the three panels while several patients were classified as TMB-high in only a subset of the sequencing panels used (Figure 1E).

Taken together, these data demonstrate that the selection of patients undergoing $\mathrm{ICl}$ treatment based on TMB is dependent on the sequencing panel used, even though all panels are equally able to predict DCB in the cohort of patients. However, our study is limited by the inclusion of only a limited dataset of 30 patients and confirmation in larger and independent cohorts is crucial. There are several harmonization efforts underway to make TMB values comparable across different sequencing panels ${ }^{13}$ and correlation has most often been used to demonstrate the comparison of different sequencing panels. However, the present study clearly demonstrates that the comparison of TMB values across different sequencing panels is inappropriate and that it might be preferable to assess the predictive performance of the respective sequencing panels independently of each other. Additionally, it seems critical to not only show the correlation of TMB values from the whole population but also from samples that are close to the calculated cut-off value to avoid overestimation of correlation based on very high TMB values. 
medRxiv preprint doi: https://doi.org/10.1101/2020.03.28.20046102; this version posted March 30, 2020. The copyright holder for this preprint (which was not certified by peer review) is the author/funder, who has granted medRxiv a license to display the preprint in All rights reserved. No reuse allowed without permission.

Acknowledgments: We would like to thank Abby Cuttriss from the Office of International Scientific Visibility at Université Côte d'Azur for proof reading. 
medRxiv preprint doi: https://doi.org/10.1101/2020.03.28.20046102; this version posted March 30, 2020. The copyright holder for this preprint (which was not certified by peer review) is the author/funder, who has granted medRxiv a license to display the preprint in perpetuity.
reuse allowed without permission.

\section{References}

1. Hellmann MD, Ciuleanu T-E, Pluzanski A, et al. Nivolumab plus Ipilimumab in Lung Cancer with a High Tumor Mutational Burden. N Engl J Med. 2018;378(22):2093-2104. doi:10.1056/NEJMoa1801946

2. Samstein $\mathrm{RM}$, Lee $\mathrm{CH}$, Shoushtari $\mathrm{AN}$, et al. Tumor mutational load predicts survival after immunotherapy across multiple cancer types. Nat Genet. 2019;51(2):202-206. doi:10.1038/s41588-018-0312-8

3. Chan TA, Yarchoan M, Jaffee E, et al. Development of tumor mutation burden as an immunotherapy biomarker: utility for the oncology clinic. Ann Oncol Off J Eur Soc Med Oncol. 2019;30(1):44-56. doi:10.1093/annonc/mdy495

4. Fancello L, Gandini S, Pelicci PG, Mazzarella L. Tumor mutational burden quantification from targeted gene panels: major advancements and challenges. J Immunother Cancer. 2019;7(1):183. doi:10.1186/s40425-019-0647-4

5. Heeke S, Benzaquen J, Long-Mira E, et al. In-house Implementation of Tumor Mutational Burden Testing to Predict Durable Clinical Benefit in Non-small Cell Lung Cancer and Melanoma Patients. Cancers (Basel). 2019;11(9):1271. doi:10.3390/cancers11091271

6. Endris V, Buchhalter I, Allgäuer $\mathrm{M}$, et al. Measurement of tumor mutational burden (TMB) in routine molecular diagnostics: in silico and real-life analysis of three larger gene panels. Int J Cancer. February 2019:ijc.32002. doi:10.1002/ijc.32002

7. Wu H-X, Wang Z-X, Zhao $\mathrm{Q}$, Wang $\mathrm{F}, \mathrm{Xu} \mathrm{R}-\mathrm{H}$. Designing gene panels for tumor mutational burden estimation: the need to shift from 'correlation' to 'accuracy.' J Immunother Cancer. 2019;7(1):206. doi:10.1186/s40425-019-0681-2

8. Alborelli I, Leonards K, Rothschild SI, et al. Tumor mutational burden assessed by targeted NGS predicts clinical benefit from immune checkpoint inhibitors in non-small cell lung cancer. J Pathol. August 2019. doi:10.1002/path.5344

9. Zhang Y, Chang L, Yang Y, et al. The correlations of tumor mutational burden among singleregion tissue, multi-region tissues and blood in non-small cell lung cancer. $J$ Immunother Cancer. 2019;7(1):98. doi:10.1186/s40425-019-0581-5

10. Kazdal D, Endris V, Allgäuer $M$, et al. Spatial and temporal heterogeneity of panel-based tumor mutational burden (TMB) in pulmonary adenocarcinoma: separating biology from technical artifacts. J Thorac Oncol. July 2019. doi:10.1016/j.jtho.2019.07.006

11. Bland JM, Altman DG. Statistical methods for assessing agreement between two methods of clinical measurement. Int J Nurs Stud. 2010;47(8):931-936. doi:10.1016/j.ijnurstu.2009.10.001

12. Vokes NI, Liu D, Ricciuti B, et al. Harmonization of Tumor Mutational Burden Quantification and Association With Response to Immune Checkpoint Blockade in Non-Small-Cell Lung Cancer. JCO Precis Oncol. 2019;(3):1-12. doi:10.1200/PO.19.00171

13. Merino DM, McShane L, Butler M, et al. TMB standardization by alignment to reference standards: Phase II of the Friends of Cancer Research TMB Harmonization Project. J Clin Oncol. 2019;37(15_suppl):2624-2624. doi:10.1200/JCO.2019.37.15_suppl.2624 
medRxiv preprint doi: https://doi.org/10.1101/2020.03.28.20046102; this version posted March 30, 2020. The copyright holder for this preprint (which was not certified by peer review) is the author/funder, who has granted medRxiv a license to display the preprint in All rights reserved. No reuse allowed without permission. 
medRxiv preprint doi: https://doi.org/10.1101/2020.03.28.20046102; this version posted March 30, 2020. The copyright holder for this preprint (which was not certified by peer review) is the author/funder, who has granted medRxiv a license to display the preprint in All rights reserved. No reuse allowed without permission.

\section{Figures}
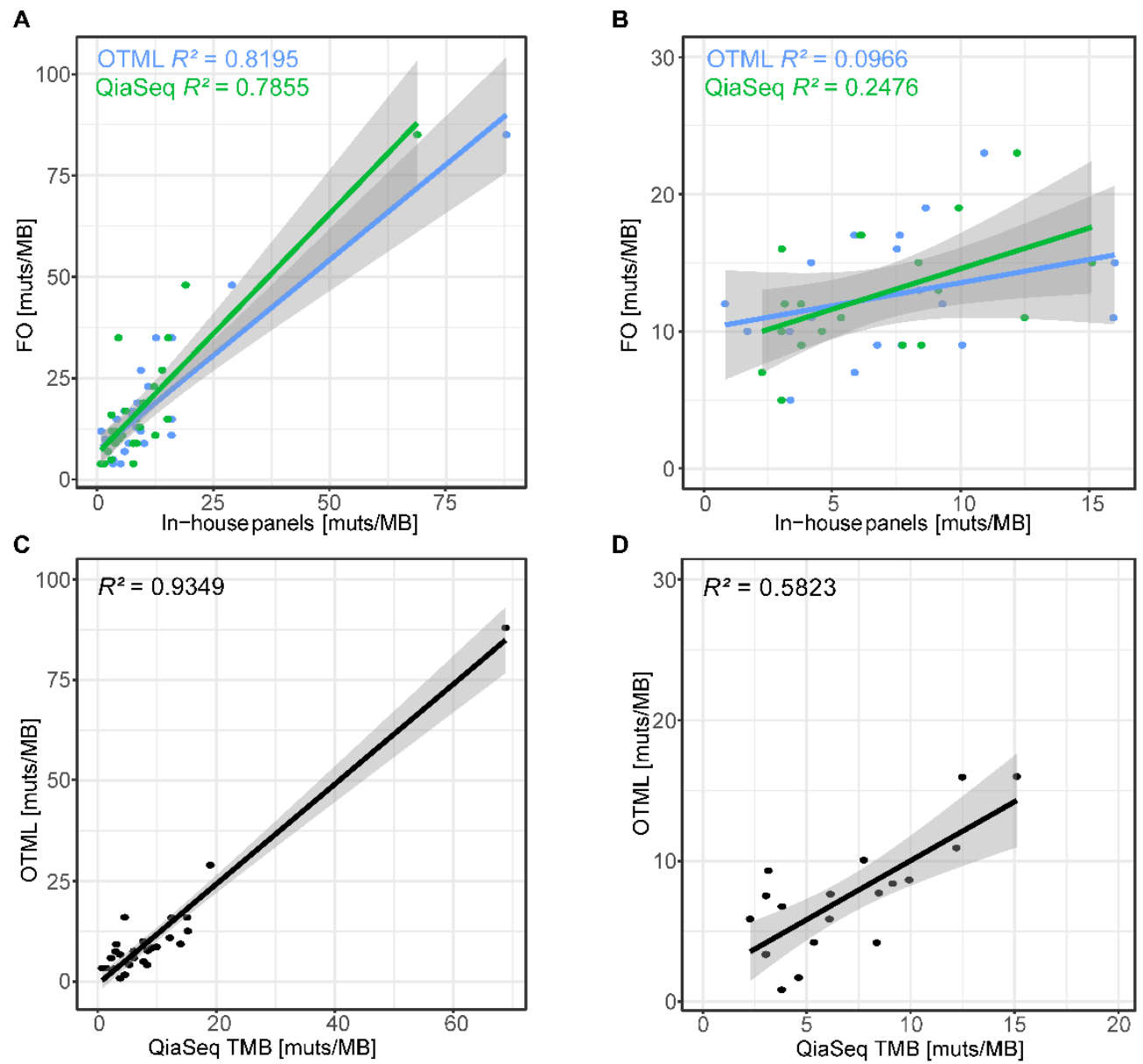

E

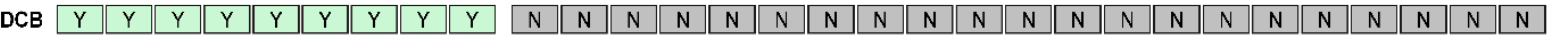

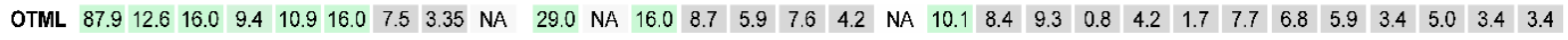

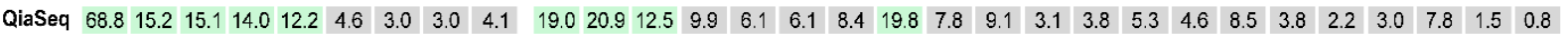

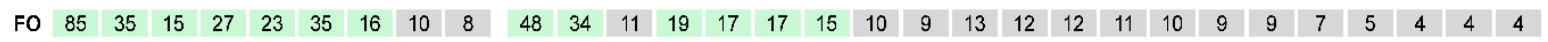

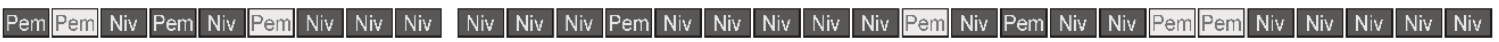

Drug Pem Pembrolizumab in first-line Pem Pembrolizumab in second-line (or later) Niv Nivolumab in second-line (or later)

Figure 1: Correlation of Tumor Mutational Burden (TMB) across three targeted sequencing panels. A) The TMB of two in-house panels (Oncomine TML = OTML and QiaSeq TMB = QiaSeq) is correlated to the TMB obtained by the outsourced FoundationOne (FO) assay and $R^{2}$ is given. B) Correlation of two in-house panels to FoundationOne in a subset of patients where the TMB as assessed by FO was between 5 and 25 mutations/Megabase (muts/Mb). C) Correlation of the two in-house tests against each other. D) Correlation of the two in-house tests in a subset of patients where the TMB as assessed by FO was between 5 and 25 muts/Mb. E) The durable clinical benefit (DCB) for each patient is given together with the TMB value obtained by the used targeted sequencing panels. TMB values that were classified to be TMB-high are highlighted in green. Lastly the respective immunecheckpoint inhibitor treatment is given in the last row. 
medRxiv preprint doi: https://doi.org/10.1101/2020.03.28.20046102; this version posted March 30, 2020. The copyright holder for this preprint (which was not certified by peer review) is the author/funder, who has granted medRxiv a license to display the preprint in perpetuity.

All rights reserved. No reuse allowed without permission.

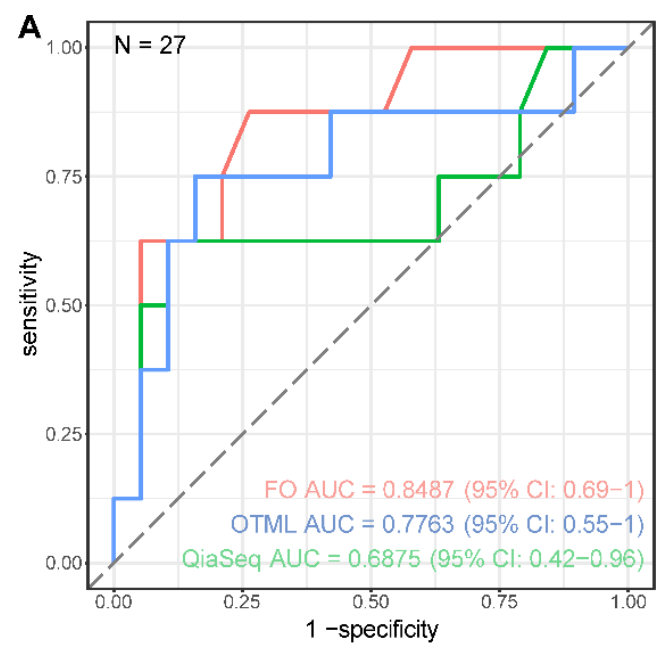

B
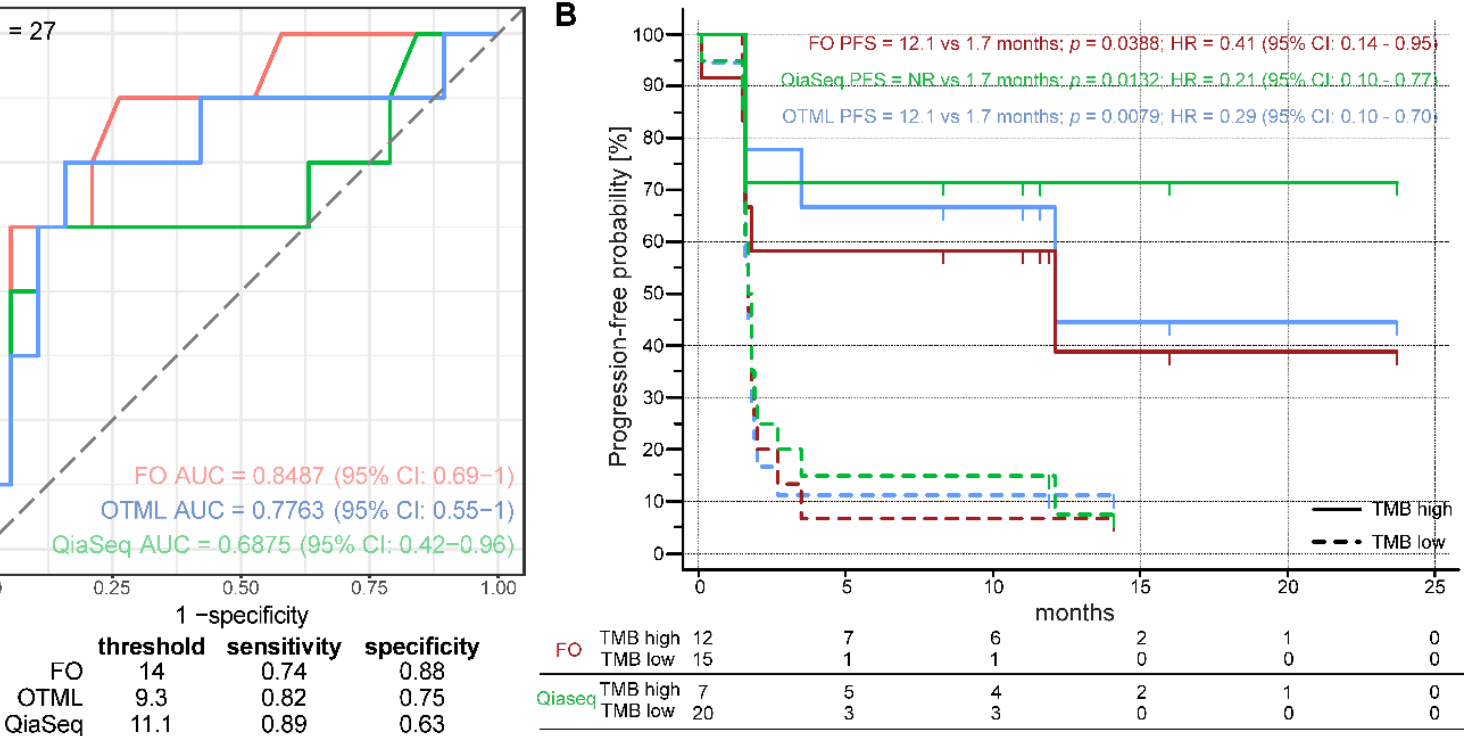

\begin{tabular}{|c|c|c|c|c|c|c|c|}
\hline FO & TMB high & 12 & 7 & 6 & 2 & 1 & 0 \\
\hline Qiaseq & TMB high & 7 & 5 & 4 & 2 & 1 & 0 \\
\hline OTML & $\begin{array}{l}\text { TMB high } \\
\text { TMB low }\end{array}$ & $\begin{array}{c}9 \\
18\end{array}$ & $\begin{array}{l}6 \\
2\end{array}$ & $\begin{array}{l}5 \\
2\end{array}$ & 2 & $\begin{array}{l}1 \\
0\end{array}$ & $\begin{array}{l}0 \\
0\end{array}$ \\
\hline
\end{tabular}

Figure 2: Clinical outcome of patients characterized by TMB. A Receiver Operator Characteristics (ROC) demonstrating the predictive performance of the targeted sequencing panels used. The area under the curve (AUC) together with the $95 \%$ confidence interval is given in the lower right corner. In total, 27 patients with successful sequencing data have been directly compared. The threshold was calculated using Youden's $J$ and is given in the table below together with sensitivity and specificity for each panel using the calculated cut-offs. B Kaplan-Meier plot for the assessment of progression-free survival. The TMB-high patients have been classified using the calculated cut-off in $\mathbf{A}$ and patients at risk are shown in the table below the figure. $p$-values were calculated using a log rank test and hazard ratio (HR) has been calculated using Cox Proportional Hazards Regression Analysis. 95\% confidence interval $(95 \% \mathrm{Cl})$ is given for the Hazard ratio.

Supplementary Material: Supplementary Table 1: Patient Characteristics; Supplementary Table 2: Comparison of different gene panels used; Supplementary Table 3: Correlation assessment of different gene panels used. Supplementary Figure 1: Venn diagram highlighting overlapping genes used across the three sequencing panels; Supplementary Figure 2: Bland-Altman analysis of pairs of TMB values for the whole and the filtered populations. 